\title{
PEMIKIRAN MITIS AKULTURATIF DALAM TEKS KI AGENG GRIBIG
}

\author{
Darmoko \\ Program Studi Jawa, FIBUI, Depok, Jawa Barat, Indonesia \\ Email: pak.darmoko@gmail.com
}

\begin{abstract}
Abstrak
Setelah Majapahit runtuh agama Islam masuk ke tanah Jawa melalui berbagai wilayah pesisir utara Jawa Timur dan Jawa Tengah. Agama Islam yang disebarkan oleh raja dan wali lalu menjadi pilar bagi kraton dan kadipaten berdiri di wilayah itu. Para wali tersebar di berbagai wilayah di Jawa Timur, Jawa Tengah, dan Jawa Barat. Ki Ageng Gribig merupakan salah satu wali yang populer di Jawa, khususnya di wilayah Jawa Tengah. Menurut sejarah, beliau keturunan ke-5 Prabu Brawijaya, raja Majapahit dengan putri Cempa. P3KAG (Pengelola Pelestarian Peninggalan Ki Ageng Gribig) telah menulis tentang riwayat Ki Ageng Gribig ini. Bagaimana perjalanan Ki Ageng Gribig dari wilayah Tuban (Jawa Timur) ke Jatinom, Klaten (Jawa Tengah) dan bagaimana kiprah beliau di tempat yang baru itu, sebagai diskusi yang menarik. Paper ini membahas Integrasi Islam - Jawa melalui kajian teks Ki Ageng Gribig yang diterbitkan oleh P3KAG. Ki Ageng Gribig sebagai salah satu wali Allah yang sangat disucikan oleh masyarakat Jawa karena giat menyiarkan agama Islam dengan memadukan unsur-unsur budaya lokal Jawa. Mitos Ki Ageng Gribig menjadi arah dan pedoman bagi masyarakat pendukungnya. Metodologi deskriptif kualitatif dan kepustakaan dipergunakan untuk menguraikan akulturasi dan mitos orang suci. Teks Ki Ageng Gribig dibahas sedetail mungkin sesuai apa adanya dan didukung dengan kepustakaan yang memadai. Hasil pembahasan mengasumsikan bahwa kebudayaan Jawa dapat menerima dan mengolah masuknya Islam untuk disesuaikan dengan kepribadian setempat. Budaya religi yang telah berkembang lama tentang penghormatan kepada dewa, roh, atau sukma diakulturasikan dengan Islam.
\end{abstract}

Kata kunci: Mitis, Jawa, Islam, wali, akulturasi

\section{ACCULTURATIVE MISTICAL THINKING IN KI AGENG GRIBIG TEXT}

\author{
Darmoko \\ Program Studi Jawa, FIBUI, Depok, Jawa Barat, Indonesia \\ Email: pak.darmoko@gmail.com
}

\begin{abstract}
After Majapahit the Islamic religion collapsed into Javanese land through various northern coastal areas of East Java and Central Java. The religion of Islam spread by the king and saint then became a pillar for the palace and duchy standing in the region. The saints are scattered in various regions in East Java, Central Java, and West Java. Ki Ageng Gribig is one of themost popular saint in Java, especially in the Central Java region. According to history, he was the 5th descendant of Prabu Brawijaya, king of Majapahit with the daughter of Cempa. P3KAG (Management of Ki Ageng Gribig Heritage Preservation) has written about Ki Ageng Gribig's history. How was Ki Ageng Gribig's trip from the Tuban region (East Java) to Jatinom, Klaten (Central Java) and how he was involved in the new place, as an interesting discussion. This paper discusses the integration of Islam - Java through the study of the Ki Ageng Gribig text published by P3KAG. Ki Ageng Gribig as one of the guardians of God is very sanctified by the people of Javanese for actively broadcasting Islam by combining elements of local Javanese culture. The Myth of Ki Ageng Gribig is the direction and guide for the supporting community. Qualitative descriptive methodologies and literature are used to describe the acculturation and myths of saints. Ki Ageng Gribig's text is discussed in as much detail as possible as it is and is supported by
\end{abstract}


adequate literature. The results of the discussion assume that Javanese culture can accept and process the entry of Islam and then adapt it to the local personality. The long-standing religious culture of respecting gods, spirits, or souls is cultured with Islam.

Keywords: Mythic, Javanese, Islam, saint, acculturation

\section{PENDAHULUAN}

Di dalam kebudayan Jawa cukup banyak kisah sejarah tentang seorang tokoh yang sakti dan populer. Kedudukan tokoh tersebut semasa hidup berhubungan dengan agama, sosial, dan kenegaraan seperti raja, pujangga, dan kyai. Tokoh-tokoh itu setelah wafat kemudian dimakamkan di tempat tertentu yang dihormati dan dirawat secara baik, seperti Sri Susuhunan Paku Buwana I-VII di Imagiri, KGPAA Mangkunagara I di di bukit Mangadeg kabupaten Karanganyar, R.Ng. Ranggawarsita, pujangga kraton Surakarta di Palar kabupaten Klaten; dan Ki Ageng Pandanaran, wali Allah di Bayat kabupaten Klaten.

Ki Ageng Gribig atau Syekh Wasibagna Timur merupakan salah satu tokoh yang sakti dan populer dipercaya masyarakat pendukungnya sebagai keturunan raja Majapahit yang binatara (manifestasi dari dewa) bernama Brawijaya, dimakamkan di Jatinom Klaten Jawa Tengah untuk menyebarkan agama Islam.

Ki Ageng Gribig erat kaitannya dengan upacara yaa - qowiyyu atau angkawiyu. Upacara ini dilakukan masyarakat di wilayah Jatinom, Klaten, Jawa Tengah. Pada bulan Sapar (bulan ke-2 pada almanak Jawa), masyarakat menyaksikan upacara tersebut. Upacara itu diselenggarakan untuk mengenang Ki Ageng Gribig ketika beliau merintis dan menyiarkan agama Islam di daerah Jatinom dan sekitarnya. Oleh karena itu banyak petilasan beliau berupa goa, masjid, surau, ara-ara, sendang, makam, dan lain-lain.

Pemikiran Ki Ageng Gribig berhubungan dengan kiprah beliau dalam hal agama, sosial-kemasyarakatan, dan politik kenegaraan, menghipnotis masyarakat pendukungnya untuk membaca dan memaknainya sebagai keteladanan Masyarakat pendukung, khususnya P3KAG (Pengelola Pelestarian Peninggalan Ki Ageng Gribig), berkeyakinan bahwa Ki Ageng Gribig semasa hidup melaksanakan darma sebagai seorang wali dengan menyelenggarakan upacara yang sampai sekarang dilestarikan sebagai yaa-Qowiyyu atau angkawiyu. Hal itu dilakukan oleh warga, karena semasa hidup Ki Ageng Gribig selalu berdakwah untuk menyiarkan agama Islam. Masyarakat 
di seputar makam Ki Ageng Gribig lalu banyak yang menjalankan ajaran yang dulu pernah diajarkannya hingga sekarang. Ki Ageng Gribig merupakan keturunan Prabu Brawijaya yang ke-5, raja Majapahit dengan Putri Cempa. Bagaimana Ki Ageng Gribig sampai di Jatinom, kaki gunung Merapi, menarik untuk dibahas, terutama tentang silsilah atau genealogi dalam kaitannya dengan mitos orang suci.

Pemikiran tentang Ki Ageng Gribig berkembang ke arah perannya dalam hal sosial-kemasyarakatan dan politik- kenegaraan. Semasa hidup Ki Ageng Gribig pernah menerima kehadiran Sultan Agung, raja Mataram, kemudian berperang dengan Adipati Kendal, pangeran Mandurareja, dan raja Palembang. Di samping itu Ki Ageng Gribig berjasa membantu Sultan Agung dikala berperang melawan Belanda di Batavia. Permasalahan sejarah dan mitos orang suci dalam teks Ki Ageng Gribig tentang peranperan di bidang keagamaan, sosial-keagamaan, dan politik-kenegaraan menunjukkan bahwa relasi antara P3KAG dan Ki Ageng Gribig erat hubungnnya dengan proses dan mekanisme pelegitimasian tokoh kharismatik. Pola pikir mitis, kosmis, magis, dan klasifikatoris di dalam teks Ki Ageng Gribig bekerja dalam proses pelegitimasian untuk mencapai keselarasan sosial antara Islam dan Jawa.

\section{METODE PENELITIAN}

Metode riset dalam artikel ini menggunakan pendekatan objektif dengan melakukan pengkajian pada objek teks karya budaya. Teks Ki Ageng Gribig sebagai teks sejarah didekati secara objektif kontekstual (Teeuw, 2013: 41). Selain itu dilakukan kajian pustaka melalui literatur-literatur yang berkaitan dengan pokok bahasan meliputi konsep citra, simbol, dan mitos. Riset ini menerapkan metode deskriptif-kualitatif dengan melakukan penjabaran objek kajian serinci mungkin dan melakukan pemaknaan melalui data-data sebagai realitas dan mengolahnya dengan analisis-analisis yang sesuai. (Soemantri, 2005: 57). Riset ini dibingkai konsep etika Jawa dengan menganalisis data berdasarkan pada nilai-nilai yang berkaitan dengan etika keselarasan dalam kehidupan masyarakat Jawa terutama mengenai kehidupan sosial dan religi.

Dalam realita sosial di masyarakat kehidupan antara manusia dan Tuhan merupakan satu kesatuan yang saling berkaitan satu sama lain. Konsep etika Jawa (Suseno, 1984: 6) menmguraikan bahwa nilai-nilai yang ada di masyarakat mengenai sikap hidup, tindakan, serta pembawaan yang seharusnya dilakukan sebagai dasar 
keberhasilan hidup manusia. Keberhasilan hidup berhubungan dengan pengakuan terhadap sistem sosial masyarakat, berbahagia, serta mampu melakukan pemenuhan terhadap takdir Tuhan. Konsep yang digunakan berkaitan dengan dunia kehidupan sosial masyarakat Jawa seperti pengendalian hawa nafsu, kedudukan pemimpin, serta takdir yang berkaitan dengan kehidupan manusia. Kesempurnaan hidup merupakan perihal lahir dan batin, yakni menjalankan tugas manusia sebagai utusan Tuhan untuk membentuk masyarakat yang sejahtera agar terwujud ketertiban serta ketentraman. Kesempurnaan hidup dapat diraih berdasarkan keselarasan antara individu serta masyarakat agar menerapkan nilai-nilai sosial sehingga mampu hidup dalam ketentraman. (Jong, 1976: 23). Konsep-konsep tersebut sebagai landasan kajian teks Ki Ageng Gribig.

\section{HASIL DAN PEMBAHASAN}

\section{Jatinom Sebagai Persinggahan Terakhir Pengembaraan Ki Ageng Gribig}

Jatinom merupakan kota kecil di wilayah kabupaten Klaten. Pada masa kolonial Belanda sebagai kota kawedanan di bawah karesidenan Surakarta. Jumlah penduduk Kelurahan Jatinom, Kecamatan Jatinom kurang lebih 2.623 jiwa, terdiri dari 1.335 lakilaki dan 1.288 wanita (Laporan Akhir Penyusunan Perencanaan Teknis Kawasan Wisata Makam Ki Ageng Gribig Kabupaten Klaten Tahun Anggaran 2007, Kantor Pariwisata Kabupaten Klaten: II.3).

Penduduk kecamatan Jatinom, Klaten terdiri dari bermacam-macam pemeluk agama (keyakinan). Pemeluk agama penduduk kecamatan Jatinom dibagi menjadi tiga, yaitu pemeluk agama Islam, Kristen Katholik, dan Kristen Protestan. Pemeluk agama Islam berjumlah 2583; Kristen Katholik 14, dan Kristen Protestan 26, adapun pemeluk agama Hindu, Budha, lan lainnya tidak ada. Ini menunjukkan bahwa penduduk kelurahan Jatinom mayoritas beragama Islam. Oleh karena itu tentang kebudayan di Jatinom mendapat pengaruh Islam, hal ini dapat terlihat dari sisi bangunan dan perilaku yang menunjukkan bahwa Jatinom sebagai kampung wilayah para santri.

Banyak upacara di Jatinom, Klaten, yang berhubungan dengan kabudayan, hingga sekarang masih hidup, ini menunjukkan bahwa semua hasil kebudayaan dipengaruhi oleh agama Islam., seperti: ruwahan, lair hingga seda, labuhan, padusan, dan yaa-qowiyyu (saparan). Kecuali itu juga mengenai kesenian yang tumbuh dan 
berkembang di Jatinom, banyak yang dipengaruhi oleh agama Islam, seperti: terbangan, santiswaran, barjanji, dan samrah atau gambus. (Laporan Akhir Penyusunan Perencanaan Teknis Kawasan Wisata Makam Ki Ageng Gribig Kabupaten Klaten Tahun Anggaran 2007, Kantor Pariwisata Kabupaten Klaten: II.4).

Jatinom tidak dapat dipisahkan dari Ki Ageng Gribig. Di dalam teks Ki Ageng Gribig diuraikan bahwa ia berasal dari wilayah Ngibig, Giri, Tuban, Jawa Timur. Terdapat empat pendapat (versi) tentang asal-usul Ki Ageng Gribig: sebagai sebagai keturunan ke-5, ke-3, ke-2, ke-1 (putra) dari Prabu Brawijaya, raja Majapahit. Pendapat yang ke-4 dipercaya P3KAG berasal dari Raden Ngabei Ranggawarsita, tetapi kitab apa dan berada di mana belum begitu jelas. Ini lah satu asumsi bahwa asal-usul Ki Ageng Gribig telah mengalami resepsi dan transformasi teks yang erat hubungannya dengan proses pelegitimasian tokoh kharismatik.

Versi pertama di diuraikan bahwa Ki Ageng Gribig sebagai keturunan ke-5 dari Prabu Brawijaya, raja Majapahit. Prabu Brawijaya mempunyai anak dari isterinya, Putri dari Cempa/ Campa, yaitu Raden Mas Guntur. Raden Mas Guntur meninggalkan ksatriaan pergi dari kerajaan akan melakukan tapa di Ujung Awar-Awar, wilayah pesisir Tuban; ia tirakat dan menjauhi keduniawian kemudian berganti nama Wasi Jaladara; kemudian menjadi ajar yang menguasai "wilayah timur". Ki Ajar Jaladara didatangi Sunan Bonang diajak bertanding tentang ilmu kebatinan. Ki Ajar kalah, kemudian masuk agama Islam dan berganti nama Wasibagna I, pada waktu itu ia diminta Sunan Bonang pergi menuju dusun Ngibig, wilayah Tuban. Wasibagna I memiliki tiga orang anak, yaitu: 1. Syekh Blacak Bilau - yang kemudian pergi untuk melakukan tapa di laut sebelah utara (Laut Jawa); 2. Syekh Pekalangan - kemudian pergi dan bertapa di laut selatan (Samodra Indonesia?); 3. Syekh Panganti - yang mengembara ke berbagai tempat. Anak yang pertama dan kedua Putra ingkang kaping-1 lan 2 tidak diceritakan, adapun anak yang ketiga, yaitu Syekh Panganti setelah demikian lama bertapa dengan mengembara ke barbagai tempat, ingat ayahnya, kemudian kembali ke Ngibig. Setelah ayahnya wafat, Syekh Panganti yang kemudian berganti nama Wasibagna II, menjadi ajar di Ngibig.

Syekh Wasibagna II memiliki satu anak, yaitu Kyai Syekh Fakir Miskin (karena ia suka memberi dana kepada fakir miskin); diibaratkan memberi tongkat kepada orang berjalan di tempat licin, memberi makan kepada orang yang kelaparan, menjadi 
penerang bagi orang di tengah kegelapan. Setelah Wasibagna II wafat, Syekh Fakir Miskin kemudian menggantikan sebagai ajar di Ngibig dan berganti nama Wasibagna III. Syekh Wasibagna III memiliki dua anak yaitu: 1. Kyai Ageng Gribig sebagai menantu Sinuhun Giri, berumah tangga dengan anak perempuannya bernama Raden Ayu Ledah; 2. Tidak diceritakan nama dan menjadi anak menantu Batara Katong di Panaraga. setelah Syekh Wasibagna III wafat, Kyai Ageng Gribig kemudian menggantikan sebagai ajar dan namanya tidak berubah, tetap Kyai Ageng Gribig. Kyai Ageng Gribig memiliki satu anak laki-laki yaitu Syekh Wasibagna Timur. Kyai Ageng Gribig wafat, kemudian Syekh Wasibagna Timur ikut ibunya ing Wanasraya, dekat makam Giri. Setelah ibunya wafat dan dimakamkan di Giri, Syekh Wasibagna Timur kemudian mengembara meninggalkan tempat tinggal ayah dan ibunya (Giri). Ia kemudian membuka wilayah baru, sebuah dukuh di wilayah Jatinom, Klaten. Di sana ia mulai menetap bernama Kyai Ageng Gribig II. Adapun riwayat kata gribig menghormati (daluri) keturunan Giri yang ada di Ngibig; jadi kata giri dan ngibig akhirnya menjadi gribig. Riwayat tersebut menunjukkan bahwa Ki Ageng Gribig merupakan keturunan Prabu Brawijaya, raja Majapahit, sebagai keturunan ke-5.

Versi yang kedua bahwa Ki Ageng Gribig di Jatinom sebagai keturunan ke-3 Prabu Brawijaya, raja Majapahit. Prabu Brawijaya memiliki anak bernama Kyai Ngujung Pawar-Pawar atau Raden Mas Guntur, Kyai Ngujung Pawar-Pawar memiliki anak Penganti Bagna. Penganti Bagna diangkat menantu Sinuhun Giri, kemudian membuka dusun di Ngibig dan populer dengan nama Kyai Ngibig. Kyai Ngibig kemudian memiliki anak Syekh Wasibagna yaitu Ki Ageng Gribig di Jatinom.

Versi yang ke-3 bahwa Ki Ageng Gribig di Jatinom merupakan keturunan ke-2 Prabu Brawijaya, raja Majapahit. Prabu Brawijaya memiliki anak bernama Jaka Dolog (anak yang ke- 101). Menurut ahli waris Ki Ageng, keterangan tersebut yang disetujui. Setelah perang Majapahit tahun 1478-1520, salah satu anak Brawijaya yang pergi meninggalkan kraton yaitu Raden Pakukunan (Pakukuhan?) dan adiknyan yang masih berusia 5 tahun (Jaka Dolog). Ia pergi sampai Kedung Siwur, wilayah Magelang. Ketika itu Jaka Dolog suka bertapa, antara lain di sungai Praga (Kedu) dengan sebutan Syekh Blacak Ngilo atau Syekh Pakir Miskin. Ia masih suka bertapa, disamping di wilayah Jawa Tengah juga wilayah Jawa Timur kemudian mengabdi kepada Sunan Giri. Setelah itu ia diambil menantu Sunan Giri mendapatkan anak perempuannya, yaitu Raden Ayu 
Ledah. Syekh Pakir Miskin diminta Sunan Giri agar membuka desa di Ngibig kemudian bernama Kyai Ageng Gribig. Ia memiliki satu anak yaitu Wasibagna (Ki Ageng Gribig di Jartinom). Ibu Ki Ageng Gribig setelah wafat dimakamkan di Wanasraya, dekat stasiun Miri, Palur.

Versi yang ke-4 bahwa Prabu Brawijaya memiliki anak bernama Raden Jaka Dolog, atau Syekh Wasibagna, juga disebut Kyai Ageng Gribig di Jatinom. Sejumlah versi sejarah asal-usul $\mathrm{Ki}$ Ageng Gribig satu dengan yang lain menunjukkan perbedaan. Perbedaan itu bagi masyarakat pendukungnya tidak menjadi persoalan penting. Mereka lebih mengutamakan pendapat garis besar bahwa Ki Ageng Gribig adalah keturunan Barwijaya dan ketika masih muda bernama Syekh Wasibagna.

\section{Sekelumit Kiprah Ki Ageng Gribig}

Setelah ibunya wafat, Syekh Wasibagna Timur (Ki Ageng Gribig) merasa sedih dan bingung. Hatinya tidak tentram, lalu bersemedi di makam kakeknya, Sunan Giri. Pada saat itu ia mendapat ilham, dan harus melakukan tapa di hutan Merbabu yang berada di kaki gunung Merapi. Ia melaksanakan Ilham yang diterimanya. Perjalanan Syekh Wasibagna Timur memasuki hutan Merbabu kemudian menemukan dua buah pohon jati, satu diantaranya masih muda dan satu lagi sudah tua. Ia bertapa di bawah pohon di antara dua pohon jati itu. Pada waktu Syekh Wasibagna Timur bertapa, di langit terdapat cahaya, sebagai tanda bahwa tapanya diterima oleh Tuhan.

Sementara, raja Mataram, Sultan Agung bersedih hati, karena Sultan Palembang akan mbalela kepada Mataram, dengan cara tidak bersedia memberikan upeti. Sultan Agung pergi menyucikan batin memohon kepada Tuhan agar terhindar dari mara bahaya. Sunan Kalijaga kemudian menemui sultan Agung, dan meminta supaya pergi ke hutan Merbabu di kaki gunung Merapi untuk menemui orang yang sedang bertapa di sana, dia lah yang akan dapat menenangkan suasana dan menghentikan Sultan Palembang mbalela.

Sultan Agung pergi menuju arah cahaya terang yang ada di langit, Syekh Wasibagna Timur telah tanggap bahwa yang hadir adalah raja tanah Jawa. Sultan Agung kemudian mengutus Syekh Wasibagna Timur untuk menangkal mbalela-nya Sultan Palembang. Syekh Wasibagna Timur dan Sultan Agung kemudian pergi menuju Palembang. Di suatu masjid Wasibagna Timur menunjukkan kesaktiannya (mukjizatnya). Ia melepas surban dan memutarnya, hingga orang-orang yang 
menyaksikannya turut berputar. Kejadian itu disaksikan Sultan Palembang, oleh karena itu Palembang kemudian takluk kepada Mataram karena kesaktian Syekh Wasibagna Timur, utusan Sultan Agung. Setelah Palembang dapat ditaklukkan kembali, Syekh Wasibagna Timur kembali ke lereng Merapi dan membuka desa Jatinom. Ketika kembali dari Palembang Syekh Wasibagna Timur kemudian diberi hadiah seorang putri, adik Sultan Agung, yaitu Raden Ayu Emas sebagai isteri. Syekh Wasibagna Timur kemudian membuka tempat yang masih berupa hutan menjadi desa, untuk bertapa, membangun masjid, dan menyiarkan agama Islam. Syekh Wasibagna Timur minta agar desa itu di kelak kemudian hari menjadi tanah perdikan, dan luasnya dengan wilayah sesuai dengan jangkauan suara bedug yang ditabih di masjid Jatinom itu. Permintaan Syekh Wasibagna Timur kepada Sultan Agung dikabulkani, kemudian ia pergi ke tanah Dwarawati dengan Raden Ayu Emas. Kepergian Syekh Wasibagna Timur dan isterinya sampai di bawah pohon jati yang dulu pernah dipergunakan untuk bertapa. Pohon jati gtersebut ditebang dipergunakan sebagai perlengkapan masjid (saka guru, bedug dan tabuhnya). Asal-usul nama "Jatinom", ketika Sultan Agung bertemu dengan Syekh Wasibagna Timur (Ki Ageng Gribig) bertapa di bawah pohon jati yang masih muda, yang kemudian tempat itu menjadi pedesaan.

Ki Ageng Gribig juga pernah diminta Sultan Agung untuk berperang ke Kaliwungu (pangeran Mandurareja). Mandurareja sebagai adik ipar (anak Pangeran Benawa di Pajang) Sultan Agung yang pernah berperang melawan Belanda di Batavia, tetapi akhirnya merasa malu dan mbalela kepada Mataram. Sultan Agung meminta agar Ki Ageng Gribig membantu memerangi Kaliwungu. Ki Ageng gribig menggelar latihan perang keprajuritan di halaman goa Belan. Sebelum itu Sultan Agung meninjau Masjid Alit, oleh karena keadaannya kecil kemudian ia berkata agar Ki Ageng Gribig membangun masjid yang lebih besar.

Ki Ageng Gribig pergi menuju ke Kaliwungu dengan nama baru Kyai Jaki Jaya, seperti nama perguruan yang ia dirikan. Pangeran Mandurareja perang tanding dengan Kyai Jaki Jaya. Pangeran Mandurareja tewas, dipotonglah lehernya oleh Kyai Jaki Jaya, badannya ditinggalkan di Kaliwungu sedangkan kepalanya diserahkan kepada Sultan Agung. Ketika Pangeran Manudrareja wafat, air sungai menjadi ungu, oleh karena itu tempat ini di kelak kemudian hari dinamakan Kaliwungu. 
Lama kelamaan Jatinom semakin ramai. Ki Ageng Gribig kadang-kadang sebagai imam masjid Jatinom, anak cucu juga ikut sholat di sana. Ki Ageng Gribig kadang-kadang sholat tarawih ke Mekah dan naik haji berkali-kali. Ki Ageng Gribig juga sering ziarah ke tanah Arab dengan Sinuhun Sultan Agung. Dikala ziarah ke Mekah dan naik haji pada tanggal 15 Sapar 1511 Jawa (Ratu Suci Tataning Jagad), Ki Ageng Gribig mendapat kue apem (roti gimbal saking Mekah) yang masih hangat kemudian dibawa pulang diberikan kepada anak cucu, dengan mengatakan "apem Yaqawiyu" dan tanah arafah yang kemudian ditanam di mighrab ara-ara Tarwiyah. Yaa-qowiyyu berarrti Gusti Allah mohon kekuatan. Nyai Ageng Gribig kemudian membuat apem untuk anak cucu karena tidak mencukupi. Hingga sekarang orang-orang Jatinom membuat kue apem dan diberikan kepada panitia ketika akan diselenggarakan upacara Yaa-qawiyyu. Orang-orang Jatinom mengadakan selamatan dengan menyelenggarakan kue apem dan dilaksanakan pada hari Jumat diseputar tanggal 15 bulan Sapar.

Pada suatu hari di bulan Sura, Ki Ageng Gribig semedi di ara-ara Tarwiyah ketika itu terdengar suara menggelegar menakjubkan dari arah gunung Merapi. Suara tersebut sebagai isyarat/ tanda akan terjadinya banjir lahar dingin. Lava pasti akan menerjang desa Jatinom menurut aliran sungai Soka. Ki Ageng mengerahkan kekuatan menghadapi lahar dingin, oleh karena itu aliran air berbelok ke selatan (banyu malang). Kecuali itu, di "ara-ara" Tarwiyah terdapat dua buah batu sebagai tempat bersujud Ki Ageng, oleh karena itu disebut pasujudan ara-ara Tarwiyah hingga sekarang dipegunakan sebagai tempat sholat Idul Fitri dan Idul Adha.

Di dekat masjid alit terdapat dua sumur, namun Ki Ageng kemudian memindahkan ke tepi sungai Soka, yang dinamakan Sendhang Suran, karena terjadinya dengan cara dikucurkan (sur-suran). Di desa Padangan terdapat ssedang Soka, airnya dapat sebagai obat bagi orang sakit, jika airnya berubah warna, akan terjadi sesuatu (biru artinya rusak).

Alkisah, sahabat Ki Ageng Gribig bernmama Sykeh Ibrahim, baru datang dari tanah Arab, akan menguji kesaktian Ki Ageng Gribig. Keduanya berbantah ilmu, samasama hebat. Syekh Ibrahim menuju sungai akan berwudhu. Air sungai menjadi kotor,. Syekh Ibrahim kemudian naik ke atas, tetapi di sana telah ada sendhang, hasil pujaan Ki Ageng Gribig. Sendhang ini disebut Sendhang Klampeyan. Ada pula sendhang yang 
lain, yaitu Sendhang Teruwes untuk mengumpulkann roh halus Jatinom, dan Sendhang Brubyah, tempat untuk transfer ilmu kepada murid-muridi Ki Ageng.

Petilasan Ki Ageng juga ada yang berupa goa, yaitu goa Belan (Pabelan), sebagai tempat untuk semedi dan sholat, ketika ia membantu dan membela Sultan Agung berperang melawan Mandurareja, Kaliwungu.

\section{Alam Pikiran Manusia dan Kebudayaan Jawa}

Menurut van Peursen (1988: 34), alam pikiran manungsa terbagi atas tiga hal, yaitu alam pikiran mitis, ontologis, lan fungsional. Di dalam alam mitis manusia merasa takut terhadap daya-daya alam dan kekuatan lama. Manungsa kuna (primitif) hidup bersama alam yang masih murni, belum terpengaruh kebudayaan dan teknik modern. Manungsa di sini memiliki jiwa seperti anak-anak, sesuatu yang dilakukan jua masih mudah untuk dicerna, tidak seperti manusia modern. Alam pikiran manungsa di sini penuh dengan kekuatan-kekuatan gaib, dilingkupi rahasia dan bergantung kepada alam, tetapi jika diteliti secara mendalam, susunan alam pikiran tidak sederhana. Kaidahkaidah tetap dihurmati dan dilakukan. Kaum rasionalis merendahkan alam pikiran mitis ini, primitif dan tidak ilmiah. Dengan demikian telah terjadi salah paham anatara primitif (romantik) dan rasionalis.

Di dalam mitos dapat dimengerti bahwa manusia mengatur strategi lanmengatur hubungannya dengan daya-daya alam. Fungsi mitos (berupa kisah) yaitu memberikan pedoman dan mengarahkan manusia. Kisah gtersebut berupa lambang-lambang yang menggambarkan pengalaman manusia pada masa lalu: lambang mengenai baik-tidak baik, hidup-mati, dosa-suci, surga-neraka, dan sebagainya. Mitos memberikan arahterhadap sikap dan perilaku manusia, seperti pedoman untuk kearifan manusia.

Alam pikiran ontologis sebagai pembebasan. Alam pikiran mitis manusia merasa takut kepada daya-daya alam. Manusia mencari strategi agar menemukan kaitan yang pas antara manungsa dengan kekuatan-kekuatan alam. Upacara diutamakan, pertimbangan teoritis dan dongeng tentang kejadian dunia diperhatikan. Tindakan praktis, seperti pertukangan, teknik, dan kesenian juga diperhatikan; dalam hal ini telah dimulai renungan teoritis mengenai alam yang tampak (fisik) dan alam yang tidak tampak (metafisik). Perkembangan pemikiran ini dinamankan perkembangan pemikiran dari mitis ke logos, bersifat logis, ini bukan berarti tentang akal budi saja, tetapi emosiemosi (tentang rasa), keinginan masyarakat serta kepercayaan (agama) tetap memiliki 
pengaruh. Arah dan tujuan filsafat dan pengetahuan yang intinya untuk maksud praktis tersebut yaitu pembebasan dari hal-hal yang berhubungan dengan kekuatan-kekuatan gaib yang menguasai hidup dan mati.

Adapun alam pikiran fungsional menunjukkan pengaruh kepada hal-hal lainnya, tidak berdiri sendiri tetapi malahan berada di dalam suatu hubungan yang menghasilkan suatu makna. Fungsional ini merupakan bagian dari kebudayaan modern. Fungsional untuk menjelaskan berbagai kejadian yang bersifat modern. Ontologi membebaskan dari magi, sedangkan fungsional membebaskan dari substansionalisme yang menyerang manusia. Tradisional dipandang tidak sesuai, asli, dan nyata. Fungsional berarti mengasingkan, sesuatu yang biasa dialaminya sebagai sesuatu yang asing, keadaan dunia serba biasa serta tampak sebagai musuh yang menakutkan, tidak menyadari terhadap pekerjaan sendiri, tidak bermakna jika dipandang lepas dari lingkungannya.

Kebudayaan Jawa jika ditelusuri secara utuh masih banyak yang berlandaskan pada pemikiran mitis, yang berhubungan dengan kepercayaan, bahasa, pengetahuan, kesenian, mata pencaharian hidup, dan sebagainya. Tetapi jika ditelaah dari masalah perkembangan pemikiran, memang yang semula masih memiliki alam pikiran mitis, kemudian berubah ke ontologis, malahan ke fungsional.

Kabudayan Jawa yang hingga sekarang banyak memuat pemikiran mitis, khususnya berhubungan dengan sastra, antara lain: kitab-kitab babad dan wayang. Kitab-kitab babad dan wayang mengandung unsur sejarah/ riwayat dan silsilah, seperti Babad Tanah Jawi dan Sejarah wayang Purwa. Kecuali itu ada lagi kebudayaan Jawa yang hingga sekarang masih lestari yaitu ruwatan (untuk membebaskan manusia dari dari mala petaka) (Darmoko, 2002: 32); biasanya upacara ini mempergelarkan wayang (lakon Sudamala atau Murwakala). Upacara ini berasal dari kabudayan prasejarah (neolitik), yaitu upacara pemujaan terhadap roh leluhur yang dipimpin seorang saman, agar roh leluhur tersebut memberikan berkah keselamatan anak cucu yang masih hidup dan memujanya itu (Hazeu, 1979: 21). Kecuali itu keberadaan upacara bersih desa atau "merti dhusun", masyarakat salah satu desa menyelenggarakan upacara syukuran karena telah menerima anugerah berupa panen padi yang baik (lakon berorientasi pertaniaan (dewi padi): Sri Mulih ataui Sri Boyong) dan telah dijauhkan dari hama tanaman, maka berbahagia untuk memboyong dewi sri ; mengenai upacara pemujaan roh nenek moyang dapat dibuktikan dengan adanya peninghgalan berupa dolmen, sarkopagus, 
penden undak-undak, menhir, dan sebagainya. Ini menunjukkan bahwa masyarakat pada pada masa prasejarah telah religius.

\section{Pemikiran Ki Ageng Gribig dalam Kerangka Kebudayaan}

Sejarah Ki Ageng Gribig yang tersebar di dalam masyarakat Jawa, kental dengan alam pikiran mitis yang diuraikan oleh van Peursen tersebut di atas. Sejarah Ki Ageng Gribig, baik sejarah maupun kiprahnya di dalam masyarakat, di bidang keagamaan, kemasyarakatan, dan kenegaraan, terkait dengan alam pikiran mitis itu. Misalnya tentang tapa, semedi atau teteki; di sini dapat diuraikan bahwa tapa merupakan usaha manusia agar mendapatkan kekuatan adi kodrati dan dapat merebut kekuatan alam; hasilnya berujud ilham, pulung atau wahyu. Bermacam-macam petun juk Illahi kepada mansuia, baik itu berupa ilham, pulung, dan wahyu, disertai tandatanda kejadian alam, seperti: turunnya cahaya dari atas (langit) ke bawah (di atas manusia yang tengah bertapa, teteki, semedi), terang tetapi tidak menyilaukan; ada lagi suara yang terdengar menggelegar, dan lain-lain. Semua menunjukkan bahwa Tuhan memberikan tanda kepada manusia melalui kejadian yang ada di alam. Isi tandatersebut bermacam-macam, dapat berupa petunjuk dan perintah biasa, anugerah tentang kekuasaan, seperti: kejatuhan pulung (pulung kraton). Orang yang kejatuhan pulung segera melakukan sesuatu yang berkaitan dengan dharma (tugas suci) yang harus dikerjakan. (Sunoto, 1987: 36).

Ki Ageng Gribig sering bertapa, "teteki”, dan semedi, oleh karena itu sering pula mendapatkan ilham. Ini terdapat di dalam sejarah Ki Ageng Gribig dan kiprahnya di dalam masyarakat. Sultan Agung menemui Ki Ageng yang tengah teteki di hutan Merbabu, kaki gunung Merapi, dia lah yang akan berhasil menenangkan suasana ketika Sultan Palembang akan mengadakan penyerangan terhadap Mataram. Sultan Agung sendiri bersemedi untuk menyucikan diri memohon kepada Illahi, pada saat itu pula Sunan Kalijaga datang dihadsapannya dan meminta agar Sultan pergi ke hutan Merbabu kaki gunung Merapi.

Manusia yang intensif untuk bertapa, "teteki", dan semedi menunjukkan bahwa dirinya senantiasa berusaha menjauhkan dari hal-hal yang bersifat duniawi, dan mengendalikan hawa nafsu. Manusia tersebut dapat "dekat" dengan Tuhannya dan akan mendapat anugerah Illahi. Ini juga telah digambarkan di dalam beberapa lakoni wayang, khususnya lakon yang terkait dengan wahyu, seperti: Wahyu Cakraningrat, Wahyu 
Kembar, Wahyu Darma, dan Wahyu Makutharama (Darmoko, 2014: 59). Jika kisah yang ada di dalam Babad Tanah Jawi, seperti wahyu kraton yang yang diterima Jaka Tingkir/ Mas Karebet, ketika bertapa dan semedi di atas rakit. Ki Ageng Butuh menyaksikan bahwa wahyu/ pulung kraton telah berpindah dan jatuh pada Jaka Tingkir, seperti kutipan berikut.

Ing wanci tengah dalu Ki Ageng Butuh medal saking griyanipun, kaget ningali pulung kraton, cumlorot saking ler kilen, dhawah wonten ing lepen panggenanipun tilem raden Jaka wau. Ki Ageng nunten nututi ing dhawahing pulung. Lajeng ginugah,"Thole, tangiya, aja pijer turu bae. Pulung kraton ing Demak wis ngalih marang sira." Raden Jaka lan sarencangipun sampun sami tangi. Lajeng binekta dhateng dhepokipun ki Ageng Butuh. (Rass, 1987: 41-42).

Terjemahannya:

'Di saat tengah malam Ki Ageng Butuh keluar dari rumahnya, terkejut menyaksikan pulung kraton caha turun dari arah barat laut jatuh di sungai tempat Jaka tadi tidur. Ki Ageng kemudian mengikuti kemana jatuhnya pulung itu. Kemudian ia dibangunkan, "Ananda, bangunlah janganlah tidur melulu, pulung kraton demak telah berpindah kepada anda" Jaka dan kawan-kawannya kemudian bangun. Mereka diajak ke rumah Ki Ageng Butuh'.

Kutipan itu menunjukkan bahwa wahyu kraton dapat diterimanya karena usaha dengan tekun, serius, dengan rasa keprihatinan. Kata "prihatin" berasal dari bentukan "kerata basa" = perih hati, "hati yang perih/ pedih"., dengan senantiasa mendekatkan diri kepada Tuhannya dengan menjauhkan hal-hal yang berkaitan dengan keduniawian dan hawa nafsu.

Fenomena tersebut dapat dimaknai bahwa kehidupan manusia tidak terlepaskan dari kekuatan alam yang bersifat adi kodrati, dan berusaha mengatur strategi agar kekuatan alam tersebut bermanfaat bagi kehidupannya. Di dalam pemikiran mitis dapat terbagi menjadi tiga sub pemikiran, yaitu pemikiran kosmis, magis, dan klasifikatoris. Di dalam pemikiran kosmis, manusia memandang bahwa alam merupakan satu kesatuan yang serasi/ harmonis, tidak lepas satu dengan yang lainnya dan selalu berhubungan. Sedangkan pemikiran magis, manusia memandang bahwa peristiwa yang terjadi di dalam alam makro sebagai akibat yang ditimbulkan oleh alam mikro, atau sebaliknya. Di dalam kehidupan alam tidak senantiasa dalam keadaan seimbang, namun juga mengalami ketidakseimbangan. Pemikiran klasifikatoris, manusia memandang bahwa kehidupan alam telah tertata rapi, masing-masing elemen menjalankan perannya 
sendiri-sendiri. Jika di dalam jagad gede tertata rapi maka di jagad alit pun juga demikian, atau sebaliknya. (Mulder, 1984: 14). Antara jagad gede dan jagad alit saling mempengaruhi. Makhluk Illahi, baik yang dianggap hidup maupun yang dianggap tidak hidup, dan kasat mata maupun yang tidak kasat mata, senantiasa menapaki kehidupan mereka sendiri-sendiri serta membutuhkan ruang dan waktu yang bergerak itu. Hasil kebudayaan Jawa yang gterkait dengan konsep pemikiran ini yaitu sistem perhitungan (pengetahuan). Sistem perhitungan yang hinga sekarang masih lestari misalnya pancawara (satu kurtun waktu tertentu yang berhari lima= Pon, Wage, Kliwon, Legi, Paing) dan saptawara (satu kurun waktu gtertentu yang berhari tujuh= Senen, Selasa, Rebo, Kemis, Jemuah, Setu, Ahad). Ketika menerapkan perhitungan antara pancawara dan saptawara dipadukan, seperti: Senen Pon, Selasa Wage, Rebo Kliwon, Kemis Legi, Jemuah Paing, dan sebagainya.

Pemikiran Ki Ageng Gribig bermuatan pemikiran mitis. Disamping mitos sebagai pedoman bagaimana manusia harus berperilaku, juga memperkokoh/ melegitimasi bahwa Ki Ageng Gribig sebagai tokoh yang hebat, sakti, keturunan raja besar titisan dewata,. Di dalam sejarah jelas dinyatakan bahwa Syekh Wasibagna Timur/ Ki Ageng Gribig dapat berpengaruh magis dengan memanfaatkan kekuatan alam yang menakjubkan, ini ditunjukkan ketika ia melepaskan surban dan diputar-putar, yang mengakibatkan orang-orang Palembang yang ada di halaman masjid, turut terpengaruh putaran surban itu bak gabah yang diputar-putar (kadya gabah deninteri), kemudian Sultan Palembang merasa belas kasihan terhadap rakyatnya itu. Disamping itu ia juga mendapatkan kemenangan berperang dengan Pangeran Mandurareja, di Kaliwungu, malahan berhasil memotong leher sang Pangeran. Ia unggul ketika berbantah ilmu dengan Sykeh Ibrahim dari tanah Arab. Hal ini menunjukkan bahwa Ki Ageng Gribig sebagai tokoh yang hebat, sakti, dan keturunan ningrat/ raja dpanci piyantun inwata, Brawijaya.

Terkait dengan kiprah Ki Ageng Gribig: ia membawa oleh-oleh roti "gimbal" (apem) dari tanah Arab ketika ziarah dan naik haji, ini menguatkan bahwa ia memiliki maksud yang mulia, yaitu melakukan ajaran Islam dengan tekun dan tertib agar dakwah/ syiar agama Islam dapat diterima siapa saja, terutama Jartinom dan sekitarnya. Apem yang bermakna (ampun = affuan) tersebut sebagai sarana agar umat Islam senantiasa berdoa mohon ampun kepada Tuhan; serta senantiasa melakukan dzikir 
kepada Illahi dengan menyebut namaNya, yaitu Tuah Yang Maha Kuat (yaa-qawiyuu); semoga diberikan kekuatan, oleh karena itu upacara "saparan" di Jatinom juga disebut Yaa-qawiyyu atau Angkawiyu (bagi orang Jawa yang tidak dapat mengucapkan Yaaqawiyyu).

Melalui pemikiran maupun petilasan yang ada: berupa artefak, upacara, dan agama masyarakat Jatinom Klaten, menunjukkan bahwa alam pikiran dan kiprah Ki Ageng Gribig mengarah pada perpaduan antara Jawa dan Islam. Kebudayaan Jawa dapat menerima masuknya Islam, tetapi Islam digarap dan diolah agar sesuai dengan kepribadian Jawa yang dulunya telah memiliki kepercayaan kepada dewa, roh, sukma (makhluk adi kodrati), setelah Islam masuk, kebudayaan antara Jawa dan Islam banyak mengandung kehidupan manusia dengan makhluk adi kodrati itu.

Akhirnya telaah tentang hubungan alam pikiran manungsa dan sejarah Ki Ageng Gribig, kental dengan pemikiran mitis dan pandangan kosmis, magis, serta klasifikatoris. (Suseno, 1993: 85). Manusia tidak dapat lepas dari pengaruh alam beserta kekuatan-kekuatannya dan berusaha agar hubungan antara manusia dengan alam senantiasa harmoni dan seimbang.

\section{SIMPULAN}

Simpulan pembahasan Akulturasi Islam-Jawa dalam Teks Ki Ageng Gribig dapat disimpilkan sebagai berikut.

Pemikiran Ki Ageng Gribig mengacu pada alam pikiran mitis serta pola pemikiran kosmis, magis, dan klasifikatoris. Manusia tidak lepas dari pengaruh lingkungan alam (kekuatan - kekuatan alam) dan selalu berusaha agar hubungan antara manusia dengan alam dapat teratur rapi (serasi - seimbang).

Alam pikiran mitis yang dikandung di dalam teks Ki Ageng Gribig, dapat dipergunakan sebagai pedoman untuk mengarahkan keyakinan masyarakat pendukungnya baik dalam hal bertutur kata, bersikap, dan berperilaku.

Alam pikiran mitis di dalam teks Ki Ageng Gribig berfungsi untuk menguatkan (melegitimasi) kepercayaan masyarakat pendukungnya yang bermuara pada pemikiran bahwa Ki Ageng Gribig dipandang sebagai manusia sakti dan kharismatik, keturunan Prabu Brawijaya dan Sunan Giri. 
Teks Ki Ageng Gribig menggambarkan akulturasi antara Islam dan Jawa. Kebudayaan Jawa mengolah masuknya Islam dengan menyesuaikan dengan kepribadian, tradisi, dan konvensi setempat. Kebudayaan Jawa yang sebelumnya telah memiliki kepercayaan kepada dewa, roh, atau sukma, sebagai makhluk Illahi yang berada di alam gaib, berpadu secara akulturatif dengan Islam yang termanifestasi ke dalam berbagai produk bahasa ritual, uapacara, kesenian, dan sejumlah petilasan.

\section{DAFTAR PUSTAKA}

Darmoko. (2002). Ruwatan Upacara Pembebasan Malapetaka: Jurnal Makara, Sosial Humaniora, Vol.6 No.1. Depok: Lembaga Penelitian UI.

. (2014). Konsep Darma dalam Budaya Jawa: Tinjauan Pada Lakon Wahyu Pancadarma. Yogyakarta: IKADBUDI Universitas Negeri Yogyakarta.

Hazeu, G.A.J. (1979). Kawruh Asal-Usulipun Ringgit Sarta Gegepokanipun Kaliyan Agami Ing Jaman Kina. Jakarta: Departemen P dan K.

Jong, de. (1976). Salah Satu Sikap Hidup Orang Jawa. Yogyakarta: Penerbitan Yayasan Kanisius.

Kantor Pariwisata Kabupaten Klaten. (2007). Laporan Akhir Penyusunan Perencanaan Teknis Kawasan Wisata Makam Ki Ageng Gribig Kabupaten Klaten Tahun Anggaran 2007. Klaten: Kantor Pariwisata.

Mulder, Niels. (1984). Kebatinan dan Hidup Sehari-Hari Orang Jawa: Kelangsungan dan Perubahan Kulturil. Jakarta: Gramedia.

Rass, J.J. (1987). Babad Tanah Jawi. Dordrecht-Holland - Foris Publication.

Soemantri, G. R. (2005). Memahami Metode Kualitatif. Makara Volume 9 no 2, 57-65.

Sunoto. (1987). Menuju Filsafat Indonesia. Yogyakarta: Hanindita Graha Widya.

Suseno, Franz Magnis. 1993. Etika Jawa: Sebuah Analisa Filsafat Tentang Kebijaksanaan Hidup Jawa. Jakarta: Gramedia Pustaka Utama.

Teeuw, A. (2013). Sastra dan Ilmu Sastra. Bandung : PT Dunia Pustaka Jaya.

van Peursen, C.A. (1988). Strategi Kebudayaan. Yogyakarta: Kanisius. 